\title{
A experiência como perturbação à prescrição na política curricular
}

\author{
Experience as a perturbation to prescription in curricular policy
}

\section{Experiencia como perturbación a la prescripción en política curricular}

\author{
Érika Uirgílio Rodrigues da Cunha' \\ Universidade Federal de Rondonópolis, Programa de Pós-Graduação em Educação e \\ Departamento de Educação, Professora. \\ https://orcid.org/0000-0002-6648-5261 \\ Cláudia Sales Ritter ${ }^{2}$ \\ Rede Municipal de Ensino de Rondonópolis, Professora. \\ https://orcid.org/0000-0003-0592-5793
}

Resumo: 0 texto compõe-se de reflexões produzidas no âmbito de uma pesquisa realizada em uma escola pública municipal no processo de formação continuada, com a participação de professores dos anos iniciais e finais do ensino fundamental, visando explicitar a não simplicidade de uma suscitada adesão à Base Nacional Comum Curricular pelas escolas. Apoiadas no pensamento de Jacques Derrida, inicialmente apresentamos as noções de différance e tradução como importantes para pensar a educação. Em seguida, as noções de experiência e alteridade nos ajudam a deslocar a perspectiva de investigação com narrativas autobiográficas de uma tradição caracterizada pela linearidade e transparência baseada na evidência para a consideração da experiência como o terreno do impossível, porque feita de alteridade. Uma reconstituição das cenas da formação de professores na escola ocupa a discussão na terceira seção, como parte da empiria da pesquisa com a qual buscamos realçar os excessos atinentes à vida e à educação. Assim, assinalamos que, na educação, não se pode prescindir da experiência, tentando demonstrar como, mesmo quando a prescrição é reiterada como desejável e possivel, num jogo que também bloqueia interpretações não restritivas de currículo e condições dignas de trabalho, ela não produz a precisão e a mesmidade requeridas pela BNCC. Defendemos, neste prisma, a irredutibilidade da experiência à prescrição, a perturbá-la como dimensão sem a qual nem a educação existiria, nem necessidade da política haveria.

Palavras-chave: Política curricular. Experiência. Alteridade.

Pós-doutora e Doutora em Educação pela Universidade do Estado do Rio de Janeiro.

Especialista em Literatura pela Universidade Federal de Mato Grosso; mestranda em Educação pela Universidade Federal de Rondonópolis. 
Abstract: The text is composed of reflections produced in the scope of a research carried out in a municipal public school, with the participation of teachers from the initial and final years of elementary school, aiming to explain the non-simplicity of a raised adhesion to the National Common Core (BNCC) by schools. Based on the thinking of Jacques Derrida, initially we present the notions of differrance and translation as important for thinking about education. Then, the notions of experience and otherness help us to shift the perspective of investigation with autobiographical narratives of a tradition characterized by linearity and transparency based on evidence to consider experience as the ground of the impossible, because it is made of otherness. A reconstitution of the scenes of teacher education at school occupies the discussion in the third section, as part of the research empiric with which we seek to highlight the excesses related to life and education. Thus, we point out that, in education, you cannot dismiss the experience, trying to demonstrate how, even when the prescription is reiterated as desirable and possible, in a game that also blocks non-restrictive interpretations of curriculum and decent working conditions, it does not produce accuracy and sameness required by BNCC. We defend, in this perspective, the irreducibility of experience to prescription, to disturb it as a dimension without which neither education would exist, nor would there be any need for politics.

Keywords: Curriculum policy. Experience. Alterity.

Resumen: El texto consiste en reflexiones producidas en el marco de una investigación realizada en una escuela pública municipal en el proceso de educación continua, con la participación de docentes de la escuela primaria, con el objetivo de explicar la no simplicidad de una adhesión elevada a la Base Nacional Común Curricular (BNCC) por escuelas. Basado en el pensamiento de Jacques Derrida, inicialmente presentamos las nociones de différance y traducción como importantes para pensar sobre la educación. Luego, las nociones de experiencia y alteridad nos ayudan a cambiar la perspectiva de la investigación con narraciones autobiográficas de una tradición caracterizada por la linealidad y la transparência, basadas en la evidencia, para considerar la experiencia como el terreno de lo imposible, porque está hecha de alteridad. Una reconstitución de las escenas de la formación docente en la escuela ocupa el debate en la tercera sección, como parte de la investigación empírica con la que buscamos resaltar los excesos relacionados con la vida y la educación. Por lo tanto, señalamos que, en educación, uno no puede prescindir de la experiencia, tratando de demostrar cómo, incluso cuando la prescripción se reitera como deseable y posible, en un juego que también bloquea las interpretaciones no restrictivas del currículo y las condiciones de trabajo decentes, no produce precisión e igualdad requeridas por la BNCC. Defendemos la irreductibilidad de la experiencia a prescripción, para perturbarla como una dimensión sin la cual ni la educación existiría, ni habría necesidad de política.

Palabras-clave: Política curricular. Experiencia. Alteridad.

Recebido em 15 de março de 2020

Aceito em 13 de julho de 2020

Publicado em 24 de setembro de 2020 


\section{INTRODUÇÃO}

Inserimo-nos neste dossiê, apresentando parte de uma pesquisa realizada em uma escola pública municipal no processo de formação continuada, com a participação de professores dos anos iniciais e finais do ensino fundamental. Buscamos responder ao propósito de pensar como têm se dado algumas reflexões contextuais em torno das "propostas curriculares em escolas, estados e municípios, destacando possibilidades e eventuais dificuldades criadas a partir da interpretação/tradução da BNCC", tal como oportuniza esta chamada. Trata-se um esforço em explicitar, via teorização curricular pós-estrutural, um compromisso com dinâmicas que resistam à economização da vida por se fazerem sensíveis aos fluxos da experiência social, plurais em se tratando de identificação, na proximidade do que defendem Miller e Macedo (2018). Por isso, tencionando explicitar a não simplicidade de uma suscitada adesão à Base Nacional Comum Curricular pelas escolas, a discussão contém o questionamento da leitura instrumental da crise na educação, se afastando desse registro afeito a padrões de aprendizagem, de atuação docente e de ensino, por entendê-lo como parte do problema educacional (LOPES, 2018).

Numa primeira seção mobilizamos noções caras ao pensamento derridiano, como différance e tradução, com as quais temos buscado pensar a educação. A segunda seção se ocupa da abordagem das narrativas autobiográficas assumida na pesquisa, também com o apoio de operadores da desconstrução, como experiência e alteridade. 0 enfoque discursivo derridiano desloca a autobiografia - em boa medida - de uma tradição de investigação caracterizada pela linearidade e transparência baseada na evidência para a consideração da experiência como o terreno do impossível, porque feita de alteridade.

Uma reconstituição das cenas da formação de professores na escola dá corpo à terceira seção, como parte da empiria da pesquisa com a qual buscamos realçar os excessos atinentes a vida e a educação. Assinalamos que na educação não se pode prescindir da experiência, tentando demonstrar como, mesmo quando a prescrição é reiterada como desejável e possível num jogo que também bloqueia interpretações não restritivas de currículo e condições dignas de trabalho, ela não produz a precisão e a mesmidade requeridas pela BNCC.

Entendemos ter, com a noção de experiência de Jacques Derrida, a possibilidade de suscitar um pensamento sobre a política (e tudo o mais que possa ser dito), como promessa de uma linguagem mais original, mas sempre inadequada e não menos violenta e forçada e estrangeira (DERRIDA, 2006). Neste aspecto, o artigo dá-se à problematização da noção de política que ronda e constitui o contexto curricular atual. 0 mesmo se dá com as narrativas 
autobiográficas - como forma de investigação da política curricular -, porque nossa escrita, como pesquisa, é também estrangeira e realçará a voz dos professores sendo já outra, pois sem poder ser a expressão de uma fidelidade. Assim, questionaremos o registro transparente da política no qual se inscreve a prescrição, reconhecendo nossa escrita sobre narrativas (a investigação) como igualmente limitada pela falta de acesso às coisas em si.

A investigação via narrativas não significa, por isso, como é romântico pensar, a defesa da escola como espaço por excelência da mudança curricular ou da verdade da política. Estamos a tomar a política nos termos do que Macedo e Ranniery (2018) têm chamado de política pública, no sentido de demarcar uma dilatação do termo que julgamos potente na pesquisa por, como defendem os autores, demarcar sua inscrição em atenção à contingência, "enfim, a vida das pessoas envolvidas na experiência educacional." (MACED0; RANNIERY, 2018, p. 741). Esta é, então, uma forma de rejeitar a compreensão verticalizada de que algo como uma política resulte de uma dinâmica linear, seja ela Top Down ou Bottom-up.

\section{DIFFÉRANCE E TRADUÇÃO}

[...] é pois o jogo do mundo que é preciso pensar primeiramente: antes de tentar compreender todas as formas de jogo no mundo. (DERRIDA, 2008, p. 61).

Assentada na ideia de que o signo é um terreno exemplar para negociar-se a desconstrução da metafísica (BEARDSWORTH, 2008), a perspectiva discursiva de Jacques Derrida tem nos servido para pensar a educação, as políticas curriculares. É a idealização instituída pelo signo, no que ele faz funcionar (e no que o sustenta) como oposição empíricotranscendental, "oposição entre o que se transmite (o significado, o logos, o mundano) e o transmitente (o significante, o mundano)"3 (BEARDSWORTH, 2008, p. 31), que são determinadas todas as demais oposições como uma relação particular entre o ideal e o material. Associando este jogo à possibilidade de escrever a condição mesma da verdade, Derrida explica (2008) como a escrita não é apenas um meio auxiliar a serviço da ciência, mas a condição de possibilidade dos objetos ideais e, assim, da objetividade científica, da objetividade como tal, da historicidade, afirmando que "A historicidade mesma está vinculada à possibilidade de escrever." (DERRIDA, 1991c, p. 48). Sua possibilidade constitutiva da verdade, tal como mais adiante a questionaremos, advém de uma exclusão radical, porque uma oposição é inteligível apenas com a exclusão de um de seus termos. Trata-se da arqueescritura, para Derrida, ou

"L... oposición entre lo que se transmite (el significado, el logos, lo mundano) y el transmitente (el significante, lo mundano)" (BEARDSWORTH, 2008, p. 41, tradução nossa). 
do que faz funcionar o télos, a condição do télos da metafísica e seus outros, que "informa os valores principais do pensamento ético e político desde Platão" (BEARDSWORTH, 2008, p. 32) e para o qual a questão do método foi sempre essencial por se valer das noções de homem transcendental (na filosofia clássica) e de abordagem empírica.

Esse paradoxo do qual vive o signo deixa ver sua desconexão com o próprio (com qualquer pretensão de propriedade, ousia, substância), interditando o literal, de maneira que, para Derrida (2011), não há signo. Não há nem uma presença a a-present-ar-se nem um fim a se alcançar, uma vez que não há uma realidade que nos precede. Se vivemos a clausura metafísica da qual nos fala o filósofo em Gramatologia (2008), isso se deve a que, na língua, apenas uma ficção de anterioridade, um vir-a-ser-signo do símbolo, pode se realizar, pois se mostra o arbitrário do signo como realidade sempre por ser significada. Com a interdição do signo, Derrida postula a ilusão e a violência conceitual na base do pensamento filosófico clássico e, simultaneamente, chama a atenção para a possibilidade mesma de conceitualidade. A clausura que nos impõe o signo se constitui pelo fato de ele funcionar como substituto da presença, o que Derrida (1991c, p. 40) diz ser uma problemática do signo e da escrita.

0 signo, diz-se correntemente, coloca-se em lugar da coisa mesma, da coisa presente, "coisa" equivalendo aqui tanto ao sentido como ao referente. 0 signo representa o presente na sua ausência. Faz as vezes dele. Quando não podemos tomar ou mostrar a coisa, digamos o presente, o ente-presente, quando o presente não se apresenta, então significamos, servimo-nos do subterfúgio do signo.

Qualquer que seja o signo, continua o filósofo, sua circulação "difere o momento em que poderíamos encontrar a coisa mesma" (DERRIDA, 1991c, p. 40), dela apossar-se, tê-la frente à frente ou mesmo ter dela uma intuição. Como uma de nós discutiu noutro trabalho (CUNHA, 2015), essa disrupção na e da linguagem, para Derrida (2011), como a ausência de liame entre termo e conceito, significante e significado, não é outra coisa senão o trabalho da temporalidade, a historicidade impondo a disrupção do sentido (da idealidade) e da conformação, a impossibilidade de origem ou simplesmente referência a si, presença, plenitude.

Beardsworth (2008) explica que a fenomenologia husserliana (sobretudo o que Husserl chama de redução fenomenológica em L'origine de la géométrie, 1962) permitiu a Derrida a radicalização da leitura saussuriana de signo. Não apenas a violência instituída pelo platonismo na oposição entre o transcendental e o empírico, o ideal e o material - infinitamente, como mencionamos de início -, mas, também "a redução que realiza Saussure da substância fônica do signo" (BEARDSWORTH, 2008, p. 40) como imagem acústica enseja a desconstrução em Derrida. Em Gramatologia, ele dedica-se a pensar na redução fenomenológica à materialidade operada pela semiologia saussuriana, explicitando como a imagem acústica não é o que 
se ouve, não é o som, mas o ato de ouvir, que, "como ato de que o som seja ouvidol,] é estruturalmente fenomênico e pertence a uma ordem radicalmente diversa da ordem do som real do mundo" (DERRIDA, 2008, p. 98). Assim, põe-se em curso a arquiescritura como a violência conceitual no télos, pois se "[...] a escritura ${ }^{4}$ constitui objetos ideais aos liberá-los dos laços de facticidade espaço-temporal" (DERRIDA, 2008, p. 186), a possibilidade de repetição do signo, nessa liberação de origem e de essência, liberação das palavras no tempo e no espaço, perfaz a condição mesma da idealidade. Como Bennington explica em obra assinada com Derrida (1996, p. 60), "a reduplicação [repetição] semeia o pânico entre todas as palavras e conceitos, não lhes permitindo ser o que são a não ser proibindo-lhes simultaneamente de sê-lo no sentido que sempre se deu à palavra (e ao conceito) 'palavra' e ao conceito (e à palavra) 'conceito'."5 Além do mais, bem pondera Derrida (1991c, p. 36, grifo do autor) que

\begin{abstract}
A escrita dita fonética não pode funcionar por princípio e por direito, e não apenas por uma insuficiência empírica ou técnica, senão admitindo em si mesma "signos" não fonéticos (pontuação, espaçamento etc.) dos quais, se lhes examinássemos a estrutura e a necessidade, rapidamente nos aperceberíamos que toleram bastante mal o conceito de signo. Mais ainda, o jogo da diferença, que Saussure apenas precisou recordar ser a condição de possibilidade e funcionamento de qualquer signo, esse jogo é ele mesmo silencioso. A diferença entre dois fonemas, que permite que estes sejam e operarem como tais, é inaudivel.
\end{abstract}

Derrida conclui: não há phonê puramente fonética se não há uma escrita puramente fonética. "A diferença que faz emergir os fonemas e os dá a entender, em todos os sentidos dessa palavra, permanece, em si, inaudivel." (DERRIDA, 1991c, p. 36, grifo do autor). Trata-se da différance, de uma diferença não mais sensível ou inteligivel, alheia ao olhar e à escuta, à idealidade, uma ordem que resiste à oposição. Différance é o termo criado por Derrida para se referir à produção incessante da diferença. 0 "a" cunhado pelo filósofo (DERRIDA, 1991c), no lugar do " $e$ " na palavra francesa différence, comparece como uma alteridade gráfica que trabalha sendo o transgressor inaudivel na semelhança fônica. Uma marca muda que evidencia o jogo de perda do sentido do termo diferença, visto que o a provém (em francês) do particípio presente, "diferindo (différant), e nos reenvia para o decurso da ação do diferir antes mesmo que esta tenha produzido um efeito constituído como diferente ou como diferença (com um e)" (DERRIDA, 1991c, p. 39). Diferir é remeter para mais tarde (retardamento, desvio, reserva). 0 a "neutraliza aquilo que o infinitivo simplesmente denota como ativo" (DERRIDA, 1991c, p. 40), como ato, como consciência em ato. Nem ativo nem passivo, diz Derrida, interditando também 
neologismos ${ }^{6}$ para différance na tentativa de expressar tal perturbação e terreno insondável, "dizendo uma operação que não é uma operação, que não se deixa pensar nem como paixão, nem como ação de um sujeito sobre um objeto, nem a partir de um agente, nem a partir de um paciente, nem a partir [...]" (DERRIDA, 1991c, p. 40). Assim, différance não é algo que alguém possa personificar (decretar, instituir por vontade ou deliberação), tampouco o que se possa indicar como um está aqui ou ali. Sua inscrição já sempre atravessou a linguagem e a língua como que imbricadas no terreno de totalidade jamais perscrutável no qual vivemos enquanto inventamos este viver. Por isso, é também temporalização e espaçamento, ou seja, "constituição originária" do tempo e do espaço. 0 espaçamento indica os intervalos sem os quais um termo "pleno" não significaria, não funcionaria (DERRIDA, 1991c, p. 45, grifo do autor), porque

\footnotetext{
É necessário que um intervalo o separe do que ele não é para que ele seja ele mesmo, mas esse intervalo que o constitui em presente deve, no mesmo lance, dividir o presente em si mesmo, cindindo assim, como o presente, tudo o que a partir dele se possa pensar, ou seja, todo o ente, na nossa língua metafísica, particularmente a substância e o sujeito. Esse intervalo constituindo-se, dividindo-se dinamicamente, é aquilo a que podemos chamar de espaçamento, devir-tempo do espaço e devir-espaço do tempo (temporização).
}

A différance, portanto, não se reduz a qualquer apropriação ontológica ou teleológica. Ela "não é, não existe, não é um ente-presente", qualquer que ele seja; "e seremos levados a acentuar o que ela não é, isto é, tudo; e que, portanto, ela não tem existência nem essência. Não depende de nenhuma categoria do ente, seja ele presente ou ausente." (DERRIDA, 1991c, p. 37, grifo do autor).

Tendo em tela a perspectiva de Saussure de que no sistema da língua não há senão diferenças sem termos positivos, diferenças conceituais e fônicas, Derrida (1991c) entende que nada no signo importa mais do que aquilo (tudo) em seu redor. 0 jogo relacional infinito permite ao signo (tentar) significar, uma vez que todo conceito se encontra submerso na cadeia diferencial, remetendo a outros conceitos (e a outros e a outros...) “E, em semelhante jogo, a diferença [também] não é mais, portanto, um conceito, mas a possibilidade da conceitualidade, do processo e dos sistemas conceituais em geral." (DERRIDA, 1991c, p. 42 ). 0 movimento do jogo (lembremos, no entanto, que não por uma simples atividade) - différance - produz as diferenças como efeitos, elas que "não caíram do céu inteiramente prontas; estão tão pouco inscritas num topos noetus como prescritas na cera do cérebro." Assim, na discursividade geral que 6er Rafael Haddock Lobo (2007), em Para um pensamento úmido: a filosofia a partir de Jacques Derrida, mais especificamente
entre as páginas 92-95. 
compõe o jogo relacional como excesso, como uma rede diferencial e diferida, como ausência de origem e presença de algo, significar é suplementar. Para Derrida somente a estrutura do suplemento é original ou originária (DUQUE-ESTRADA, 2002), ou seja, ela é. Os suplementos (isto é, tudo, termos ou referentes) trabalham nessa ausência de correspondência, nessa falha na representação, que é também o dínamo de uma falta de unidade (totalidade/objetividade) ou plenitude. Se trata de uma estrutura permanentemente corroída pela tradução. Derrida explicita essa corrosão originária, essa falta de acesso, falta por assim dizer, em A farmácia de Platão (1991a) ao se valer do mito de invenção da escrita para interpô-la como um suplemento que se doa à infinita substituição, "Uma substituição que se opera, pois, como um puro jogo de rastros e suplementos ou, se queremos ainda, na ordem do puro significante que nenhuma realidade, nenhuma referência absolutamente exterior, nenhum significado transcendente vem bordejar, limitar, controlar." (DERRIDA, 1991a, p. 34-35).

Como substituta da fala, a escrita somente mimetiza o pensamento originário: o traduz. "[...] como tradução da intenção, por violência, por arrombamento, [ela] se desenvolve em um movimento contínuo e subversivo de substituição" e se coloca como o "indecidível sintomático da différance." (LOPES; CUNHA; COSTA, 2013, p. 399). De tal maneira, a tradução se impõe na impossibilidade da univocidade de uma estrutura fechada de significação ou de uma língua universal (DERRIDA, 2006, p. 72) como "o labor infinito por rejuntar." A partir disso que é Babel, não se pode mais conferir transparência ao mundo, pois Babel nos torna (a todos) tradutores, impedindo fixar a significação numa rede continuamente diferencial e diferida (FERREIRA, 2009). Assim, Derrida (2006, p. 69) assevera que "a experiência é tradução", e nos lembra em Limited Inc. (DERRIDA, 1991b) que ela é o que se traduz em relação às estruturas ditas reais, a todos os referenciais possíveis. Num gesto quase sempre mal compreendido, o filósofo concebe essa estrutura em geral como um texto, ${ }^{7}$ realçando a linguagem como o terreno instável, sem fundo fixo, em que a experiência se tona possível como tal. "Mas isso quer dizer que todo referencial, toda realidade tem a estrutura de um traço diferencial e só nos podemos reportar a esse real numa experiência interpretativa. Esta só se dá ou só assume sentido num movimento de retorno no diferencial." (DERRIDA, 1991b, p. 203).

Porquanto, chegamos ao ponto que nos interessa nesta discussão, qual seja, a possibilidade de pensar a dimensão da experiência como o que não pode ser decifrado, repetido, reproduzido, medido, comparado, transportado. De perturbar a política, que não se realiza sem a experiência mas por ela, através dela. A discussão da experiência nos mobiliza sobremaneira, porque, na educação, parte considerável das tradições pedagógicas sempre 
aspiraram detê-la de algum modo, para explicá-la como tal ou para antecipar-se a ela numa qualquer promessa de tranquilidade. Em discussão recente, uma de nós (ALMEIDA; CUNHA, 2017) abordou a proposta de campos de experiência na Base Nacional Comum Curricular para a Educação Infantil, uma vez que nela a experiência é inscrita como se possível fosse tornar a tudo claro e distinto desde uma conexão direta com conhecimentos, numa suposta literalidade da experiência como conhecimento. Dessa discussão nos vale aqui reiterar a experiência como algo que não se pode pensar a partir de qualquer plenitude, pois a coisa mesma sempre escapa (DERRIDA, 2008). Não para aventarmos o pensamento de controle que a redução da experiência a conhecimento mensurável produz, mas para, com Derrida, pensarmos tal termo sob rasura, experiência como que "não mais acenando a um acesso às coisas mesmas", senão "à estrutura de não-presença das coisas, a um movimento do que se poderia talvez chamar de realidade." (HADDOCK-LOBO, 2013, p. 265). Essa estrutura de não presença Derrida nomeia de rastro. Em Margens da filosofia (1991c), ele explica o rastro como trace, ponderando que não deve ser confundido com o traço, pois diz respeito às marcas deixadas por uma passagem, ação ou vestígios.

lgualmente noutro trabalho, uma de nós (CUNHA; COSTA, 2019) pôs em questão a expectativa de controle edificada pelo pensamento mais recente de Michael Young, ao pensar(mos) o currículo como experiência em tradução. Na ocasião, a visão de que currículos padronizados (mínima ou maximamente) são capazes de emancipar aquele sujeito conhecido pelo pressuposto (CUNHA; COSTA, 2019, p. 159) foi enfrentada pela problematização dessa insistência em uma forma de conhecer via disciplinas científicas - o conhecimento poderoso -, baseada numa então necessária assepsia da experiência. Em aproximação a essa discussão, temos como fundo, aqui, um pensamento sobre o currículo como experiência em tradução. É o que propomos pensar via investigação de narrativas autobiográficas na escola, não sem questionar parte dessa tradição de pesquisa.

\section{NARRATIUAS AUTOBIOGRÁFICAS, EXPERIÊNCIA E ALTERIDADE}

Uma outra linguagem e outros pensamentos buscam-se através dessas dificuldades. (DERRIDA, 1991b).

Portanto, não se trata de uma crítica no sentido restritivo do termo, mas sim de uma tentativa de, ao mostrá-la ou ao retratá-la sob rasura, alargar o próprio conceito de experiência, a fim de que, talvez, não mais acenando a um acesso às coisas mesmas, ele possa apontar à estrutura de nãopresença das coisas [...] (HADDOCK-LOBO, 2013, p. 265). 
Na pesquisa em tela, temos nos dedicado a discutir a experiência como lugar da relação com o outro, sendo que "Nosso mergulho na relação com o outro explicita nossa crença na educação como um processo de subjetivação que só pode ocorrer na relação com a alteridade." (MLLER; MACED0, 2018, p. 951). A pesquisa é parte de um esforço em teorizar a educação como acontecimento, o que se confunde com o próprio ato da linguagem (DERRIDA, 1991c), pois tem a ver com a experiência do viver. Com tal referência já podemos defender a experiência como constituída pelo discurso, como algo (im)possível, dado a ser feita de traço na ausência de qualquer plenitude ou presença. Já podemos também reivindicar a não simplicidade da política curricular, nos valendo igualmente da noção de alteridade.

Temos buscado pensar essa problemática via investigação de narrativas autobiográficas numa abordagem não linear e não individualista das vidas dos professores e professoras, voltada às dimensões constitutivas do processo educativo, da formação continuada de professores, das questões curriculares. Miller (2014, p. 2051) vincula tais dimensões ao incognoscível, ponderando que fazem parte da natureza mesma da experiência educacional, como "detalhes bagunçados da vida", e que se tornam mais prementes como questões não respondíveis num cenário de acentuação da cultura da testagem, que impõe medições a tudo: ao processo educativo, à formação continuada de professores, às questões curriculares etc.

Seria familiar a lógica de controle a tradição de pesquisa baseada em histórias (necessariamente) felizes ou edificadas em práticas docentes e discentes bem sucedidas. Como Miller (2014) adverte, essa tradição credencia estereótipos em torno das diferenças, que são mantidos "em sua aparente unidade somente através de processos ativos de exclusão baseados em construções estereotípicas de gênero, raça, classe, habilidade e várias outras configurações de posição de sujeito possíveis nos 'selves "8" (MLLER, 2014, p. 2058, grifo do autor). Elas dão corpo às abordagens assentadas em convenções normalizadas de pesquisa e da prática educativa, de acordo com a autora. Tendem a ser "reforçadas quando se supõe autobiografia como automaticamente igual a acesso sem mediação ao 'conhecimento de uma experiência"' (MLLER, 2014, p. 2059, grifo do autor) na busca de se produzir evidências e soluções universais para problemas pedagógicos, assim como para elaborar produtos, materiais, corrigir problemas dentre outras pretensões. Assim, ainda que se dediquem às histórias de professores, essas abordagens de pesquisa tendem a legitimar a normatização, interessadas que estão em estabelecer regularidades aos processos educativos, se valendo, inclusive, de narrativas dominantes na formação sustentadas pela afirmação da ignorância de si (do professor) e dos outros. Elas acentuam, explica Miller, noções automatizadas de formação e prática ao reiterarem perspectivas de conversão e vitória, para as quais os professores somente ignoram, nada sabem até serem iluminados.

Do inglês, “Eus”, tradução nossa. 
Miller (2014) pontua seus esforços em trabalhar com tal abordagem e, simultaneamente, em trabalhar autobiograficamente como uma luta contra essencialismos e concepções padronizadas de currículo e de pedagogia, contra seus efeitos para todos nós como pesquisadores/as e professores/as, tornando possível pensar "- ao invés de rejeitar - o divergente, paradoxal, inesperado e desconhecido da vida em sala de aula." (MLLER, 2014, p. 2060). Ela sugere ser importante encarar, na teorização curricular, os excessos, como histórias, contextos, aspectos emocionais e econômicos, sociais, de alunos e professores, que transbordam muito além do que tem sido significado como educação, currículo, pedagogia, numa teorização apegada ao cálculo. Tais dimensões, Miller nos lembra, se recusam a serem fossilizadas por perspectivas de regulação. Nesse sentido, a autora se vale dos estudos de ancoragem psicanalítica e pós-estrutural de Peter Taubman, para quem trabalhar com os excessos implica considerar eventos e pessoas, "[...] tensões geradas pelas complexidades, pela 'situacionalidade' e pelas problemáticas envolvidas no ensino, enquanto simultaneamente criando e tentando 'entender' currículo dentro das suposições, restrições e mandatos da 'cultura da testagem." (MLLER, 2014, p. 253, grifo do autor).

Na esteira de tais críticas, Miller e Macedo (2018) consideram que "Há algo na crença autobiográfica - que talvez esteja também em nossa "promessa de 'mudança da escola" - de que precisamos desconfiar." Elas mencionam Pollock (2009) ao realçar na teorização o trato transparente de noções como história, noções positivadas por uma presença, quando, muitas vezes, as representações do eu e do outro na escrita investigativa sempre já emergem como realidades composicionais afetadas por interesses particulares le por questões inconscientes, acrescentaríamos). Assim,

\footnotetext{
Não é que os professores não vivam experiências que pudessem vir a narrar, grafar, refletir sobre, mas que tais experiências não são nem suas nem acessíveis a si. Em nossa (também) "crença" no potencial disruptivo de "situações particulares", queremos expressar, não sem dificuldades, que há limites, opacidades, na capacidade dos sujeitos de dar conta de si para si e para os outros. (MLLEER; MACED0, 2018, p. 953, grifo do autor).
}

Sublinham, destacando a abordagem histórica de Scott (1991), que a experiência, muitas vezes, pode ser mobilizada como um fundamento, sobretudo quando enaltecida como transcendental e incontestável, num realismo pretencioso de circunscrevê-la como evidência. Ainda com Scott (1991), Miller e Macedo (2019) explicitam a experiência como fenômeno linguístico, arguindo por sua natureza discursiva, tal como entende Foucault. Avultam como Scott (1991) se valeu dessa perspectiva para questionar a noção moderna de sujeito autocentrado, consciente, de subjetividade e de identidade, esteio da crença autobiográfica. Miller e Macedo (2019) pontuam, neste prisma, que a experiência não é do sujeito, ele não a tem; ela é o que torna possível o sujeito como ordem (, portanto, criação) discursiva. 
Voltemos à nossa discussão sobre tradução e différance, para lembrarmos d"a impossibilidade radical de acesso às coisas enquanto elas mesmas como condição de possibilidade de qualquer experiência." (HADDOCK-LOBO, 2013, p. 260). Lembremos também que, para Derrida (1991c, p. 40), “Quando não podemos tomar ou mostrar a coisa, digamos o presente, o ente-presente, quando o presente não se apresenta, então significamos, servimo-nos do subterfúgio do signo." Ora pois que falamos da experiência como um possível (impossivel) do impossível, "outro nome aqui para alteridade" HADDOCK-LOBO, 2013, p. 269), na relação com o signo interditado, que é também o transbordamento da escritura a introduzir uma heterogeneidade radical na ordem da possibilidade. Estamos longe de defender a experiência como um ser ou estar na educação e/ou no currículo (uma prática discursiva) dotado de transparência; longe de supor que o texto da pesquisa transporta a experiência por simplesmente pesquisarmos em escolas com os professores e professoras. Não é uma crença no acesso direto a uma evidência que nos faz pesquisar currículo via narrativas autobiográficas, senão a possibilidade mesma de complicar ou de assumir como complexa (precária, talvez seja o melhor termo) essa dimensão da experiência (inefável) como relação à alteridade, relação a uma heterogeneidade intransponível que arromba o signo e da qual ele vive. "Uma linguagem outra e outros pensamentos buscam-se através dessas dificuldades." (DERRIDA, 1991b, p. 210).

Esse entendimento não se fecha à pesquisa com narrativas autobiográficas, porque, se assim fosse, estaríamos acreditando no problema do acesso à coisa mesma como uma questão de método. Na etnografia, na pesquisa com documentos, imagens, entrevistas, qualquer que seja o suporte (a superficie de inscrição), estamos a lidar com o texto no texto geral, condição da experiência. De tal modo, a relação com a alteridade que nos interpõe a experiência não é relação a algo verdadeiro, porque situado em uma topografia lum lócus de pesquisa, por exemplo), mas relação a uma significação, condição de significação, "devir-tempo do espaço e devir-espaço do tempo, "constituição originária" do tempo e do espaço, diriam a metafísica ou a fenomenologia transcendental na linguagem que é aqui criticada e deslocada." (DERRIDA, 1991c, p. 39, grifo do autor). Alteridade diz respeito - não somente à relação com um outro qualquer sujeito encarnado que não existe num fora da linguagem, mas - a uma alienação originária da língua do que nunca se perdeu, porque nunca pertenceu a ninguém (DERRIDA, 2016). Por isso, heterogeneidade absoluta e instauradora da experiência, um nome para a desconstrução "como a própria experiência da possibilidade (impossível) do impossível", como nos faz lembrar, mais uma vez, Haddock-Lobo (2013, p. 269).

Falar a experiência - derridianamente - é arriscar-se a dizer sobre as sobras, os restos nunca totais que dinamizam a significação por exclusão. Não para demonstrar um jogo lógico ou uma gramática, senão para realçar o excesso a perturbar a tranquilidade da convenção, a gramaticalidade, a intenção, que também é naturalização, sedimentação. Não significa, por isso, supor o estancamento da diferença, “.... porque ela própria não 'è nada fora 
dos diferentes determinados [...]; ela não se detém em nenhuma parte, absolutamente, e não é negatividade ou nada [...]" (DERRIDA, 1991b, p. 204, grifo do autor). Falar da experiência passa por ter em conta a espectralidade, como Derrida a pensa em Espectros de Marx (1994), e que Borges (2015, p. 30) com ele entende ser a condição mesma de (constituição de) um discurso - de um sujeito - "por atravessamentos, pela alteridade (totalmente Outro), em contraposição ao primado metafísico que clama pela reunião, pela comunhão e pela unidade que é sempre cunhada a ferro e fogo, com violência, muitas vezes, ocultada fazendo parecer natural". Este gesto (ater-se a experiência) também pode ser pensado como tentativa de desviar-se dos fundamentos edificantes dos muitos discursos sobre ser professor, ensinar, educar que Borges (ldem) considera aportarem-se na base do dogmatismo -, para dar a ver as sedimentações que os comportam em sua estrutura de promessa. Desviar-se e permitir que sejam conhecidos no sentido de um conhecimento não mais subserviente à evidência.

Portanto, não se trata de uma crítica no sentido restritivo do termo [experiência], mas sim de uma tentativa de, ao mostrá-la ou ao retratá-la sob rasura, alargar o próprio conceito de experiência, a fim de que, talvez, não mais acenando a um acesso às coisas mesmas, ele possa apontar à estrutura de não-presença das coisas, a um movimento do que se poderia talvez chamar de realidade. Nesse sentido, rastro aparece (sem aparecer) não como um conceito, mas como esta "estrutura sob rasura" das coisas, e a experiência entre aspas, ou experiência do rastro, não é a experiência de algo, nem de nada, mas um certo rastro de experiência, que é, por sua vez, a estrutura de toda experiência possível. (HADDOCK-LOBO, 2013, p. 265, grifo do autor).

Trata-se de um esforço para pensar a experiência sob o prisma do espectro e, portanto, como remessa a uma pluralidade, pois "Nunca somos assombrados por apenas um fantasma, uma horda infindável de alteridades nos obsedia [...]" (HADDOCK-LOBO, 2013, p. 270). De deslocar a pesquisa para o desconforto por não se pretender soluções ou alternativas, já que é desde esse desconforto que a alteridade radical é possível e que é possível respeitá-la, como bem indicam Miller e Macedo (2019). As autoras também têm em conta, com base no neomaterialismo de Barad (2007), como a escrita investigativa já é sempre sobre uma difração, posto que "os fenômenos ou as experiências narradas na autobiografia não repousam no passado ou são trazidas do passado ao presente, eles se difratam em uma 'multiplicidade de processos', simultaneamente, em várias temporalidades." (MLLER; MACEDO, 2019, p. 958, grifo do autor). A alteridade segue sendo, na pesquisa e na vida e na educação, dimensão inerradicável e assombro do passado e do presente. Temos em vista, então, pensar como, ante à espectralidade que não admite a unificação de sentidos (BORGES, 2015), certa estabilidade na significação nos permite transitar, por assim dizer. 
Levar em conta uma certa estabilidade (por essência sempre provisória e finita, é precisamente não falar de eternidade ou solidez absoluta, é levar em conta uma historicidade, uma não-neutralidade, ética, política, institucionalidade. [...] objeto de acordos bastante confirmados, para que se possa apoiar em laços estáveis, logo demonstráveis, entre conceitos e coisas [...] (DERRIDA, 1991b, p. 207, grifo do autor).

Essa ilusão de estabilidade opera os enquadramentos com os quais transitamos na educação como uma inteligibilidade mesma disso que chamamos educação, currículo, educar, docência, formação de professores etc. Nossa atenção na pesquisa se volta a eles como discursos/interpretações suturados/as pela contingência. Podem ser problematizados como apoios em sua não naturalidade, em sua não necessidade, o que nos permite pleitear a não simplicidade da política curricular e, simultaneamente, não simplicidade da pesquisa e desta escrita. E dizemos podem ser por nos afastarmos de uma ontologia e, não sem dificuldades, acenarmos para a originalidade e radicalidade da experiência mesma como experiência do impossivel. Sem presença mas urgente, sem acesso mas marcante.

Assumindo a ancoragem pós-estrutural, passamos à discussão de elementos que tomamos como implicados na produção da política de currículo, caracterizando sua não simplicidade. Nos valemos da perspectiva autobiográfica sem sugerir linearidades acerca das histórias de vida dos professores e professoras para explicar o que ocorre na escola. Não há pretensão de explicação do tipo causa e efeito. 0 que queremos é afirmar a escola e a educação como atravessadas e compostas, de modo inerradicável e irredutível, pela vida dos professores, alunos e pais, e, igualmente, realçar a política curricular sendo produzida pelo que de incontornável e, muitas vezes, intangível, comporta o viver. Nesse sentido, pretendemos dar vazão a aspectos disruptivos nas cenas de formação (e não a uma totalidade qualquer), tanto porque não podem ser prescritos/antecipados nas recomendações e propostas nos textos curriculares, quanto porque não podem ser bloqueados no momento mesmo em que os professores educam, falam sobre ou criam as condições para educar. Também vale dizer que a reconstituição dos cenários, como empiria da pesquisa, não logra a transparência nem a verdade da formação encaminhada na escola ou da política curricular a lhe dar vulto. Ela é tradução, como também a política assim é, porque feita de experiência aberta à alteridade.

\section{NA NÃO SIMPLICIDADE DA POLÍTICA}

Quando a política de Base Nacional Comum Curricular foi aprovada, no final de 2017, boa parte da literatura na área produzida sobre o tema da centralização curricular, sobretudo aquela apoiada em referenciais pós-críticos (Cunha (2015), Cunha e Lopes (2017) e 
Frangella, Axer e Rosário (2017), apenas para exemplificar), em alguma medida discutia o que Lopes (2015, p. 118) chamou de "uma redução da política curricular à política de conhecimento a ser ensinado e a ser aprendido nas escolas." Essa produção se projeta pela interpretação cultural do currículo e, ao mesmo tempo, pelo não abando das discussões em torno do conhecimento, sendo caracterizada por uma perspectiva antirrealista, que problematiza os fundamentos das visões cientificistas e o relativismo implicado no multiculturismo, para o qual tudo vale em termos de conhecimento (LOPES; MACEDO, 2012).

A eleição de Jair Bolsonaro à presidência, em 2018, trouxe novo viés ao cenário de centralização em curso, dada a ascensão da extrema direita no país. Por isso, se antes falávamos do controle marcado pelas tradições instrumentais e críticas, mais recentemente passamos a lidar com disputas por uma nova cultura educacional, antagônica ao que a direita nomeia de marxismo cultural (LOPES, 2019). Tais disputas não são consequência do momento anterior no campo ou no país, mas se valem da mesma lógica realista de conhecimento acentuada pelas políticas do momento anterior. Assim sendo, é sob um crescente controle curricular que realizamos a pesquisa. Especificamente, ela tem se dado nos momentos de formação continuada realizados por uma escola da rede pública municipal de ensino, desde março de 2019, quinzenalmente, envolvendo até quarenta e oito pessoas, entre professoras da equipe diretiva e professores e professoras da educação infantil e do ensino fundamental.

Para esta discussão mobilizamos parte da empiria produzida nos encontros e também recorremos a documentos curriculares, como a Base Nacional Comum Curricular (BRASIL, 2017). Pautada por uma lógica racional e determinista de educação, a BNCC (BRASIL, 2017) foi projetada como uma fórmula da equidade e da igualdade educativa e social.

Com a Base, vamos garantir o conjunto de aprendizagens essenciais aos estudantes brasileiros, seu desenvolvimento integral por meio das dez competências gerais para a Educação Básica, apoiando as escolhas necessárias para a concretização dos seus projetos de vida e a continuidade dos estudos. (BRASIL, 2017, p. 5).

A perspectiva essencialista reiterada pela tradição crítica curricular, que significa currículo como conhecimento e a aquisição do conhecimento com igualdade e equidade, é embalada pelo comportamentalismo, numa articulação que permite a leitura de que a vida das crianças e jovens poderiam, no futuro, estar integralmente formados. Expressões como "garantir", "aprendizagens essenciais", "competências gerais", "escolhas necessárias", "concretização", "desenvolvimento integral", "projetos de vida" atuam eliminando o acaso, o improviso, constituindo a promessa de um sujeito formado, que sabe como será, para um mundo que se supõe saber qual é. Ao lado dessa certeza, não há demandas pela implementação da BNCC por parte da escola, que é levada a participar de atividades do que 
seria a adaptação da BNCC às especificidades regionais e/ou locais, por um chamado externo, tal como professoras relatam num momento de formação continuada.

- Ele assim, a questão que ele passa, é uma questão de que fazer um currículo único né. Não sei se chegou ao seu conhecimento, mas, nós, do município, é ... todas essas disciplinas, estamos sentando já há umas três semanas e reelaborando diretrizes curriculares do município, mas com base na BNCC. Mas aí, assim, nós analisamos e ai desde o primeiro aninho ao nono ano. (Professora Eva).

- No meu grupinho nós estamos de três pessoas, nós pegamos desde o primeiro aninho até o nono ano em história. Então, nós pegamos material proposto pela BNCC que foi estudado pela SEDUC e ai nós estamos fazendo a nossa parte. Aí, o que a SEDUC propõe ela orientou que nós podemos mudar. Da BNCC, ela la especialista da Secretaria Municipal de Educação - SEMED] falou que não pode mudar nada, não pode tirar nada, mas pode acrescentar e ai, assim, muito produtivo, porque tá acrescentando bastante (risos). Por exemplo, o meu é história e aí a gente... Eu aprendi muito com as pedagogas, fiquei encantada! Até tô querendo fazer pedagogia só pra entender e ajudar. (Professora Berê) (informações verbais).

Parte dos trabalhos em torno da BNCC se dá como acréscimo de conteúdos relativos à parte diversificada, como dispõe a Lei de Diretrizes e Bases da Educação Nacional n. 9394/1996, Artigo 26, visto que a Secretaria do Estado de Mato Grosso - SEDUC (MT) está elaborando o Documento de Referência Curricular para Mato Grosso - concepções para a educação básica (DRC) (MATO GROSSO, 2018), possibilitando a professores do município, com vínculo profissional também na rede estadual de ensino, participar da agenda de sua produção.

Para isso, em sua organização, o documento situa, no primeiro tópico, o contexto de produção da BNCC; salienta quanto ao modo como ela deve ser apropriada pelas escolas; alude aos princípios pedagógicos que fundamentaram a sua elaboração para um ensino de garantia dos direitos à aprendizagem e desenvolvimento de competências e habilidades. Ao expor tudo isso, justifica-se a necessidade de construção do Documento de Referência Curricular para Mato Grosso e faz-se a articulação e o alinhamento dos princípios da base nacional com o currículo local. (MATO GROSSO, 2018, p. 3).

Um jogo de causa e efeito simplifica o terreno educativo (social), sugerindo-se a não contextualização radical de eventos, histórias e sentimentos que produzem qualquer interpretação. Haveria princípios pedagógicos determinados pela BNCC a serem transportados ao Documento de Referência Curricular para Mato Grosso - concepções para a educação 
básica (DRC) (MATO GROSSO, 2018), como condição mesma de inserção das escolas e professores na política. Por isso, o alinhamento dos princípios é não apenas desejado, ele já atua como - prenúncio de uma vigília dos contextos, que tende a produzir efeitos de diferenciação entre escolas e professores. Também assim aceita-se a ideia de adaptação curricular e, simultaneamente, de currículo unitário, porque municípios e estados são levados a agir em nome do que seria essa tal parte diversificada do currículo (compreendido como um programa) e de um autorizado acréscimo de conhecimentos a um núcleo essencial da formação das crianças e jovens: a base. De modo ambíguo e contraditório, a base comum é curricular, mas ela não seria o currículo da escola, dos estados e dos municípios, que precisam trabalhar por ela, em termos de compreensão, e por seus próprios currículos em termos de construção linear com esse centro. Neste gesto, certa ideia de decisão concernente à escola e aos entes federados é outorgada pela BNCC como necessária, embora ela seja não mais que uma possibilidade edificada pela contingência, ou seja, pela interpretação binária comum/diverso ou complementar, entre projeto/implantação, entre global/local, a significar o currículo e que a política mesma põe em curso.

\footnotetext{
Além disso, BNCC e currículos têm papéis complementares para assegurar as aprendizagens essenciais definidas para cada etapa da Educação Básica, uma vez que tais aprendizagens só se materializam mediante 0 conjunto de decisões que caracterizam o currículo em ação. São essas decisões que vão adequar as proposições da BNCC à realidade local, considerando a autonomia dos sistemas ou das redes de ensino e das instituições escolares, como também o contexto e as características dos alunos. (BRASIL, 2017, p. 16, grifo nosso).
}

A ideia de decisão (de decisões na ação) estofa muitas das críticas à verticalidade da política e, ao mesmo tempo, confunde quem concebe o currículo como um programa. Ao projetar um cenário de atuação, de elaboração de novos documentos, de reuniões, ao fazer circular cronogramas, orientações de especialistas, compor grupos e afetos, a BNCC dispara identificações. Assim, se realiza na precariedade de sua condição de política, de texto a ser lido por uma pluralidade de histórias e experiências, dentro de outras histórias, de quantas histórias se possa contar.

- Uma coisa, nossa! A gente trabalha em ciências e evolução e eu dou uma olhada pra nós aqui. Como qualquer coisa, nós passamos por processos e transformações na educação e política pública e nós estamos lá, lutando e fazendo. Só que a gente cumpre com a política que vem, a gente... Podemos nos organizar, nos adaptamos, nós não deixamos de cumprir. Quem não cumpriu não foi o professor, na escola ciclada que o governo quis implantar e não foi implantado. Faltou ele implantar pra que desse resultado muito melhor. Tinha possibilidade. No começo, é óbvio que eu também não 
gostava, né? Mas, a possibilidade era muito grande de dar certo, mas faltou ele. Mas era outro período, outro processo, outra ideia. Essa ideia agora o governo vai fazer de tudo pra acontecer porque é econômica. 0 governo vai fazer tudo para acontecer, não vai deixar dessa forma, não vai deixar como aconteceu, não vai deixar assim, porque faltou isso. Não. Ele vai fazer a gente cumprir o que ele quer, ele vai achar meios pra que a gente faça isso. Avaliações e tudo mais em cima da gente, vai avaliar o profissional, nós teremos avaliações por profissional, com certeza, pra ver se você estará fazendo realmente, né? Nós seremos, assim, pressionados, haverá um outro momento agora. Mas eu vejo que o governo, agora, o interesse dele é muito grande, porque o interesse dele é financeiro. (Professor Lúcio) (informação verbal).

De tal modo, a identificação/subjetivação se faz no endividamento da centralização, dada a crença num acesso total ao currículo comum (a política pensada como projeto) e ao fato de que muitas políticas evocam o professor e as escolas como protagonistas da mudança educativa. Tanto que certa culpa precisa ser afirmada, uma vez que não está em jogo duvidar dessa fortuna, de um tal conhecimento ou de como ele encarrega a escola e interdita visões de conhecimento, de currículo e de educação. A ideia de culpa é apoiada pela interpretação de fracasso escolar, que segue como linguagem a enunciar uma educação plenamente decifrada em habilidades, competências, descritores consequentes a um sujeito que sabe, que aprende. Essa linguagem que deu vida à organização em ciclos localmente, ${ }^{9}$ noutros tempos, agora profetiza a continuidade do abandono da escola e dos professores como já há muito em curso. Não obstante, se a sintomatização da negligência perfaz o não cumprimento de um projeto progressista de educação, tal como a literatura crítica sobre ciclos hegemonicamente anuncia, agora ela é lida como dada, porque não mais conectada a um projeto educativo e sim vinculada a um projeto econômico de certos grupos sociais. É de se ressaltar que nas discussões na escola têm sido recorrentes relatos e questões sobre as mudanças em curso no ensino médio, a partir dos quais se interroga seu desmonte para fins de privatização da oferta, de destituição do direito subjetivo à educação.

A afirmação da adaptação curricular, por sua vez, convive com críticas acerca do controle, que passam pelo questionamento da capacidade de agentes externos em pensar pela e para a escola, pelas avaliações externas baseadas numa padronização impossível e não desejada, porque alheia aos processos educativos em curso e para os quais os professores dispensam, cotidianamente, atenção. São questões recorrentes e não estabilizadas como posições de alguns docentes, que manifestam, vez ou outra, angústias e tensões sobre as dinâmicas (de afeto, de conflitos) com as crianças e jovens em classe, com os pais, como também sobre os conteúdos e habilidades e competências encomendados pela BNCC. 
Assim, para além da garantia de acesso e permanência na escola, é necessário que sistemas, redes e escolas garantam um patamar comum de aprendizagens a todos os estudantes, tarefa para a qual a BNCC é instrumento fundamental. (BRASIL, 2017, p. 15).

- E é muito relativo, também, na hora de você montar o que realmente você quer. Às vezes, se você fizer uma questão diferente dentro daquele assunto, o aluno consegue demonstrar que ele tem habilidade, como, às vezes, é colocada a pergunta num contexto e a criança não atinge... Muitas vezes, [ela] tem capacidade, tem competência, tem habilidades pra muitas coisas, mas o que vai ser cobrado vai ser outra, paralelamente ali, que não vai cumprir a avaliação dele. Você, como professor, com outro tipo de avaliação, às vezes, daria o aluno como apto. Á, vem uma avaliação pronta e acabada que vai dizer que ele está inapto. (Professor José).

- Ninguém consegue trabalhar aquele tanto de conteúdo que eles colocam lá não. [...] Eu já fui professora de matemática. Vou solicitar, pelo menos, umas oito aulas de matemática para dar conta de trabalhar tudo que aparece lá, senão... (risos) vai dar desgraça! (Professora Marta).

- Eles acreditam nessa política mesmo? (Professora Dirce).

- Quem? (Pesquisadora).

- É, esses especialistas que fazem essas... Você sabe o que eu sinto? Se você quer fazer um trabalho mesmo, você não consegue respirar, porque a gente tem que ficar aqui atento com a questão da climatização dentro da escola, a questão de prestação de contas [...] Então, assim, eu, particularmente, me sinto muito sobrecarregada mesmo. [...] eu sinto que nós, enquanto professores em sala de aula, tem hora que, por conta dessas coisas politicas inovadoras e essas propostas maravilhosas, a gente acaba ficando também muito sobrecarregado. (Professora Dirce) (informações verbais).

0 esgotamento profissional, o cansaço, o acúmulo de tarefas, dentre outras queixas, são tematizados nos encontros como questões com as quais os professores lidam e fazem seu trabalho e como indagação à pertinência dessa lógica de controle na política. Há também momentos em que é posta à vista a fragilidade da política em apostar na não interferência da escola sobre parte do currículo, como quando, em discussão sobre o avanço do conservadorismo no país, professores que atuam nos anos finais desta escola municipal e no ensino médio em escolas da rede estadual lembraram como conduzem suas escolhas, seu trabalho, numa perspectiva de decisão bastante distinta daquela requerida pela BNCC.

- No de Língua Portuguesa, tem um autor que a gente gosta muito dele, que é o William Cereja e ele foi tirado do programa, e a gente foi atrás para saber o que ocorreu, né? Por que que, de Língua Portuguesa, o Cereja não estava nas opções? Ele acabava sendo, assim, bastante escolhido, porque ele trazia uma proposta mais dialógica da linguagem, trabalhava com gêneros, dentro de uma ideia de contexto de produção, de recepção. E aí, a informação que foi dada é que o Cereja foi cortado do PNLD, porque ele trazia muitos textos políticos e muitas tirinhas da Mafalda, aquela personagem argentina que questiona as questões do mundo, da política, 
do ser humano. Então, ele foi julgado impróprio. [...] Porque se você acredita que, com seus alunos, você tem que fazer uma discussão que extrapola as visões do livro que chegou pra escola, você vai fazer. Você vai ensinar o que você acha que é contraditório? Você vai ensinar alguma coisa que tem o carimbo da BNCC, mas que você não concorda com aquilo? Como é que a gente faz esse processo? (Professora Ana).

- Não! E, por exemplo, os quadrinhos da Mafalda, eu posso muito bem acessálos, imprimi-los e depois trazer para discussão na aula, na construção dos textos, do sentido. Isso não vai impedir que o professor extrapole aquilo que está previsto. (Professora Helen).

- Na Geografia também trazia, Ana, e o novo [livrol que eles fizeram, eles tiraram todas as tirinhas da Mafalda. Não tem mais. Nos exercícios, tinha alguns exercícios que tinha, então eles tiraram. (Prof. José).

- E depois de tantos anos que o Cereja participou do processo, foi simplesmente cortado, porque o livro dele foi julgado inadequado para as necessidades da escola brasileira. (Professora Ana).

- Então, aí o professor de Português que gosta de trabalhar naquela perspectiva do Cereja, como é que ele vai dar aula? (Pesquisadora).

- Vai ter que adaptar o que tem, né? (Professora Helen).

- Ou fazer seu próprio material. (Professora Ana) (informações verbais).

Assim, embora demonstrem cansaço e questionem se uma política prescritiva pode cumprir o que promete, os professores decidem e trabalham a partir de sua formação inicial na universidade, que exaltam muitas vezes, de suas crenças sobre a profissão e de uma ética em torno do que seja educar que buscam ter como horizonte. Entretanto, nas situações de escolha dos autores e dos livros, dos assuntos e das atividades, essa ética da atuação não parece reivindicar um currículo comum suposto como consequente à igualdade e à equidade, tampouco é apresentada como uma lista de princípios que carregariam consigo estabilizados em competências e conhecimentos comuns. De modo distinto, ela sugere que os professores sabem e podem decidir e que decidem sempre em diferentes situações. Por isso, essa ética não é tida por eles como um conjunto de pressupostos, mas parece estar implicada na menção a situações muito pontuais, muito singulares, em momentos em que agiram avaliando suas condições de trabalho, os materiais existentes ou a serem inventados e que, também, foram apoiadas por parcerias em projetos conjuntos que desenvolveram nas escolas por onde passaram e em aspectos das tradições disciplinares que tanto afirmam como reinventam. Trata-se, pois, de uma decisão não delegada, mas sempre necessária e sem fundamento único nem fixo, decisão que ocorre o tempo todo e em diferentes lugares e situações, consciente e inconscientemente, como leitura/agência, como experiência do impossível, subjetivação.

Muitas outras questões têm nos chamado atenção na pesquisa e há um esforço em discutir algumas, visando, sobretudo teorizar acerca dessa não simplicidade da política, o que aqui optamos em fazer apoiadas na discussão derridiana de tradução, experiência e alteridade. 


\section{REITERANDO PONDERAÇÕES}

Julgamos que as cenas aqui reconstituídas/traduzidas podem ser importantes para se ter em conta a tradução a corroer a pretensão de transparência e transporte que insiste em conformar políticas curriculares centralizadas. Ancoramos tais cenas na perspectiva da experiência como tradução (assim, a experiência como algo impossível), não para dar conta da verdade da escola, da prática, mas, distintamente, para pensar no jogo disparado por um contexto interpretativo marcado por crescente controle.

Por considerarmos a experiência como da ordem da alteridade - da heterogeneidade, abertura radical ao porvir - nossa discussão realçou o pensamento derridiano de interdição do signo, que é o transbordamento da linguagem, da não contenção do texto, do sentido e, assim, a possibilidade mesma da experiência e da política. Assumimos a dificuldade de transitar neste registro, que tem na différance seu operador mais instigante, por carregar, ele mesmo, a marca do jogo inaudivel da alteridade a inscrever a experiência como um para além. Toda a primeira parte do texto foi dedicada a esta questão, que se apresenta disseminada na ampla obra derridiana, de maneira que tentamos apenas sinalizar uma ancoragem para a nossa pesquisa.

A segunda parte da discussão foi empreendida num esforço para perturbar pretensões de neutralidade na pesquisa, indicando a ideia de que nossa escrita (investigação) sempre já se encontra afetada (atravessada, recomposta) pela experiência sem acesso a, ela mesma é experiência. Neste sentido, na terceira seção, buscamos remeter ao jogo em que se processa a experiência tracejada por alteridade, ao trabalharmos com a pesquisa autobiográfica na escola, tencionando avivar alguns excessos como eventos e sentidos alheios à lógica prescritiva na educação. Alheios mas não indiferentes, não sem violência, uma vez que há constrangimentos, angústias, dúvidas, desconfiança, medos, contextos discursivos a conformarem, precariamente, leituras e subjetivações. Alheios, pois, mesmo quando sentidos de prescrição são reiterados, a coisa em si não se realiza como tal, como transporte incontaminado de uma qualquer essência a conformar-se no agora da experiência, como mesmidade.

Excessos, entendemos, não são nem superáveis, nem elimináveis, nem indesejáveis. Eles constituem dinâmicas do viver na educação, como historicidade, e a política, que é sempre necessária neste desajuste essencial da linguagem. Excessos também não são explicáveis ou sabidos em totalidade. Dizem respeito às possibilidades de interpretar que sempre estão em curso na orfandade do signo, como contextos provisórios, contingentes e incertos, porque delimitados por exclusão. 
Por isso, a autobiografia significa atenção à impossibilidade de unicidade (de sentidos) na política por respeito ao viver. Ela assinala, aqui, a dimensão da experiência sem a qual a educação não existiria e sem a qual, tampouco, haveria necessidade da política.

\section{REFERÊNCIAS}

ALMEIDA, R. S. de; CUNHA, É. V. R. da. Campos de experiência na Base Nacional Comum Curricular (BNCC): evocando o conhecimento a ser ofertado na educação infantil. In: LOPES, A. C.; OLIVEIRA, M. B. de. Políticas de currículo: pesquisas e articulações discursivas. Curitiba: CRV, 2017. p. 149-167.

BARAD, K. Meeting the universe halfway: quantum physics and the entanglement of matter and meaning. Durham: Duke University Press, 2007.

BEARDSWORTH, R. Derrida y lo político. Buenos Aires: Prometeo, 2008.

BORGES, V. Espectros da profissionalização docente nas políticas curriculares para a formação de professores: um self para o futuro professor. 2015. Tese (Doutorado) - Universidade do Estado do Rio de Janeiro, Rio de Janeiro, 2015. Disponível em: http://www.proped.pro.br/. Acesso em: 17 out. 2019.

BRASIL. Ministério da Educação. Secretaria Nacional de Educação Básica. Base Nacional Comum Curricular. Brasília, DF: MEC, 2017. Disponível em http://basenacionalcomum.mec.gov.br/. Acesso em: 10 set. 2019.

CUNHA, É. V. R. da. Política curricular de ciclos como o nome da democracia: o caso de Rondonópolis (MT). 2015. Tese (Doutorado em Educação) - Universidade do Estado do Rio de Janeiro, Rio de Janeiro, 2015. Disponivel em: http://www.proped.pro.br/. Acesso em: 10 out. 2019.

CUNHA, É. V. R. da; LOPES, A. C. Base Nacional Comum Curricular no Brasil: Regularidade na Dispersão. Investigación Cualitativa, v. 2, p. 23-35, 2017. Disponivel em https://ojs.revistainvestigacioncualitativa. com/index.php/ric/article/view/68. Acesso em: 27 nov. 2019.

CUNHA, É. V. R da; COSTA, H. H. C. Da expectativa de controle ao currículo como experiência em tradução. Revista Práxis Educacional, v. 15, n. 33, p. 141-163, jul./set. 2019. D0l: https://dx.doi.org/10.22481/ praxisedu.v15i33.528. Disponivel em: http://periodicos2.uesb.br/index.php/praxis/article/view/5280. Acesso em: 10 dez. 2019.

DERRIDA, J. A escritura e a diferença. São Paulo: Perspectiva, 2011.

DERRIDA, J. A farmácia de Platão. São Paulo: lluminuras, 1991a.

DERRIDA, J.; BENNINGTON, G. Jacques Derrida. Rio de Janeiro: Zahar, 1996.

DERRIDA, J. Espectros de Marx. Rio de Janeiro: Relume-Dumará, 1994. 
DERRIDA, J. Gramatologia. São Paulo: Perspectiva, 2008.

DERRIDA, J. Limited lnc. Campinas, SP: Papirus. 1991b.

DERRIDA, J. Margens da filosofia. Campinas, SP: Papirus, 1991c.

DERRIDA, J. 0 monolinguismo do outro. Chão de Areia: Belo Horizonte, 2016.

DERRIDA, J. Torres de Babel. Belo Horizonte: Editora UFMG, 2006.

DUQUE-ESTRADA, P. C. Derrida e a escritura. In: DUQUE-ESTRADA, P. C. Às margens: a propósito de Derrida. Rio de Janeiro: Ed. PUC-RIO; São Paulo: Loyola, 2002.

FERREIRA, É. Tradução/desconstrução: um legado de Jacques Derrida. Revista de Letras, v. 49, n. 2 , p. 229-242, jul./dez. 2009. Disponivel em: https://periodicos.fclar.unesp.br/letras/article/view/2050. Acesso em: 14 nov. 2019.

FRANGELLA, R. de C. P.; AXER, B.; ROSÁRIO, R. S. L. Políticas curriculares em uma lógica centralizadora e escapes possíveis: tecendo outras redes políticas. Revista E-curriculum, v. 15, p. 1176-1207, 2017.

HADDOCK-LOBO, R. Notas sobre o trajeto aporético da noção de experiência no pensamento de Derrida. Educação e Filosofia. Uberlândia, v. 27, n. 53, p. 259-274, jan./jun. 2013. D0l: https://doi. org/10.14393/REVEDFLL.issn.0102-6801.v27n53a2013-p259a274. Disponivel em: http://www.seer.ufu.br/ index.php/EducacaoFilosofia/article/view/14271. Acesso em: 20 dez. 2019.

HADDOCK LOBO, R. Para um pensamento úmido: a filosofia a partir de Jacques Derrida. 2007. Tese (Doutorado em Filosofia) - Pontifícia Universidade Católica do Rio de Janeiro, Rio de Janeiro, 2007.

LOPES, A. C. Apostando na produção contextual do currículo. In: AGUIAR, M. A.; DOURADO, L. C. (org.). A BNCC na contramão do PNE 2014-2024: avaliação e perspectivas. Recife: ANPAE, 2018. p. 26-30. Disponivel em: https://www.anpae.org.br/website/noticias/424-2018-05-24-18-14-11. Acesso em: 15 set. 2018.

LOPES, A. C. Articulações de demandas educativas (im)possibilitadas pelo antagonismo ao "Marxismo Cultural". Arquivos analíticos de políticas educativas. v. 27, n. 109, p. 1-21, set. 2019.

LOPES, A. C.; CUNHA, E.; COSTA, H. H. Da recontextualização à tradução: investigando políticas de currículo. Currículo sem Fronteiras, v. 13, p. 392-410, 2013. Disponível em: www.curriculosemfronteiras.org. Acesso em: 15 dez. 2019.

LOPES, A. C.; MACEDO, E. Currículo e cultura: o lugar da ciência. In: LIBÂNEO, J. C.; ALVES, N. Diálogos entre didática e currículo. São Paulo: Cortez, 2012. p. 152-167. 
LOPES, A. C. Normatividade e intervenção política: em defesa de um investimento radical. In: MENDONÇA, D.; LOPES, A. C. (org.). A teoria do discurso de Ernesto Laclau: ensaios críticos e entrevistas. São Paulo: Annablume, 2015. p. 117-147.

MACEDO, E.; RANNIERY, T. Políticas públicas de currículo: diferença e a ideia de público. Currículo sem Fronteiras, v. 18, n. 3, p. 739-759, set./dez. 2018. Disponivel em: www.curriculosemfronteiras.org. Acesso em: 10 nov. 2019.

MLLER, J. L.; MACEDO, E. Políticas públicas de currículo: autobiografia e sujeito relacional. Práxis Educativa, v. 13, n. 3, p. 948-965, set./dez. 2018. D0l: https://dx.doi.org/10.5212/PraxEduc.v.13i3.0018. Disponivel em: http://www.revistas2.uepg.br/index.php/praxiseducativa. Acesso em: 10 nov. 2019.

MLLLER, J. Teorização do currículo como antídoto contra/na cultura da testagem. E-curriculum, v. 12, n. 3, p. 2043-2063, out./dez. 2014. Disponivel em: http://revistas.pucsp.br/index.php/curriculum. Acesso em: 10 dez. 2019.

MATO GROSSO. Secretaria de Estado de Educação. Documento de Referência Curricular para Mato Grosso: concepções para a educação básica (DRC). Cuiabá: SEE, 2018. Disponível em: https://sites. google.com/view/bnccmt/educa\%C3\%A7\%C3\%A3o-infantil-e-ensino-fundamental/documento-de-refer\%C3\%AAncia-curricular-para-mato-grosso Acesso em: 1 nov. 2019.

POLLOCK, D. Beyond experience. Cultural Studies $\square$ Critical Methodologies, v. 9, n. 5, p. 636-646, jun. 2009. DOl: https://doi.org/10.1177/1532708609338036.

SCOTT, J. W. The evidence of experience. Critical Inquiry, v. 17, n. 4, p. 773-797, jun./ago. 1991. D0I: https://doi.org/10.1086/448612.

Endereço para correspondência: Avenida dos Estudantes, 5055, Cidade Universitária, Rondonópolis, Mato Grosso, Brasil; erikavrcunha@gmail.com 